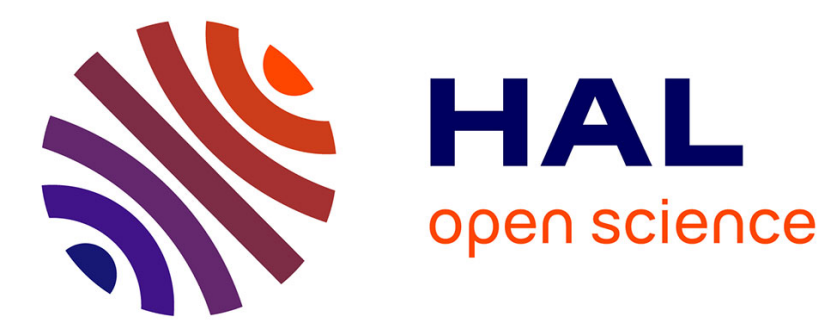

\title{
A Concept for Diamond Overlayers on Nitride Heterostructures
}

E Kohn, M Dipalo, M Alomari, F Medjdoub, J.-F Carlin, N Grandjean, S

Delage

\section{- To cite this version:}

E Kohn, M Dipalo, M Alomari, F Medjdoub, J.-F Carlin, et al.. A Concept for Diamond Overlayers on Nitride Heterostructures. Device Research Conference, Jun 2008, Santa Barbara, United States. hal-03281278

\section{HAL Id: hal-03281278 \\ https://hal.science/hal-03281278}

Submitted on 8 Jul 2021

HAL is a multi-disciplinary open access archive for the deposit and dissemination of scientific research documents, whether they are published or not. The documents may come from teaching and research institutions in France or abroad, or from public or private research centers.
L'archive ouverte pluridisciplinaire HAL, est destinée au dépôt et à la diffusion de documents scientifiques de niveau recherche, publiés ou non, émanant des établissements d'enseignement et de recherche français ou étrangers, des laboratoires publics ou privés. 


\title{
A Concept for Diamond Overlayers on Nitride Heterostructures
}

\author{
E. Kohn*¹, M. Dipalo ${ }^{1}$, M. Alomari ${ }^{1}$, F. Medjdoub ${ }^{1}$, J.-F. Carlin², N. Grandjean ${ }^{2}$, S. Delage ${ }^{3}$ \\ ${ }^{1}$ University of Ulm, Albert Einstein Allee 45, Ulm, Germany \\ ${ }^{2}$ EPFL, CH 1015, Lausanne, Switzerland \\ ${ }^{3}$ Alcatel-Thales III-V Lab, Route de Nozay, F-91460 Marcoussis, France
}

\begin{abstract}
The development of diamond overlayers with high crystalline quality for high power devices in $\mathrm{Si}$, GaAs or $\mathrm{GaN}$, aimed at heat extraction from the top, has been a quest for many years. Recently CMOS circuits have been coated by untra-nano-crystalline-diamond (UNCD) grown at $350{ }^{\circ} \mathrm{C}$, however with low thermal conductivity due to a substantial graphitic grain boundary content [1]. Usual growth conditions for nanocrystalline diamond (NCD) films of high thermal conductivity are a temperature above $600{ }^{\circ} \mathrm{C}$ in hydrogen atmosphere with high $\mathrm{H}^{*}$ radical concentration and $\mathrm{CH}_{4}$ growth chemistry. In fact, no such overlayer with high thermal conductivity has been developed to our knowledge up to now for GaAs or GaN. However, GaN based power devices are already presently seriously limited by their thermal losses and even the employment of diamond substrate heat spreaders may not be sufficient. Such substrate heat spreader configurations are usually realized by joining prefabricated semiconductor and diamond materials stacks by alloying or wafer bonding.
\end{abstract}

On the other hand, diamond overlayers of high crystalline quality could serve also other purposes like as inert electrochemical electrode for operation in highly corrosive and hazardous environments to detect (and oxidize) almost all hazardous organics like phenols or biomolecules like dopamine [2]. In addition, with a diamond electrode GaN based ChemFETs (in HEMT configuration) could operate in the amperometric as well as potentiometric mode, whereas Si-MOS-ISFETs can only operate in the potentiometric mode.

In this investigation NCD has been grown at conditions, which are typical for electrode applications [3], at a temperature of approx. $700{ }^{\circ} \mathrm{C}$ and $\mathrm{CH}_{4}$ chemistry on an InAlN/GaN heterostructure with $10 \mathrm{~nm}$ InAlN thickness. The InAlN/GaN heterostructure can be grown lattice matched on GaN, thus avoiding stress induced defect formation at high temperature; and indeed (in contrast to the AlGaN/GaN system), it has shown to possess a high thermal stability up to at least $1000^{\circ} \mathrm{C}$, when used in a HEMT configuration [4]. It was therefore chosen for this investigation.

Fig. 1 shows the surface morphology of a $200 \mathrm{~nm}$ thick NCD film deposited onto this InAlN/GaN heterostructure in a $2 \mathrm{hr}$ deposition process at $700{ }^{\circ} \mathrm{C}$ in a Hot Filament reactor and $0.3 \% \mathrm{CH}_{4}$ in $\mathrm{H}_{2}$. Fig. 2 shows the corresponding Raman spectrum. Both, the grain structure and the $\mathrm{sp}^{3}$ diamond peak are clearly identified. Fig. 3 shows the surface of the heterostructure mesa surrounded by the GaN buffer after diamond deposition. For diamond nucleation, a $\mathrm{SiO}_{2} /$ amorphous Si PECVD (20nm/120nm) interfacial layer had been deposited. As can be seen, the InAlN surface morphology is not degraded, whereas blistering is seen on the GaN surface, again indicating the high ceramic-like stability of the InAlN surface.

$\mathrm{Ti} / \mathrm{Al} / \mathrm{Ni} / \mathrm{Au}$ ohmic contacts and Ni/Au Schottky contacts have been deposited after overgrowth and removal of the overlayer. The corresponding output characteristics are shown in fig. 4. Open channel current level, pinch-off voltage and transconductance are not essentially degraded. This means that the crystallinity of the heterostructure interface and the polarization discontinuity have not been degraded. On the other hand, the high leakage current illustrates the degradation of the GaN buffer. Thus, in respect to diamond overlayers for heat extraction, the InAlN/GaN heterosystem is viable candidate, however at the same time GaN buffer layer passivation is essential.

For the ChemFET application the NCD film has been deposited onto the Ni-gate contact pad. The diamond film had been quasi-metallically boron doped to allow amperometric operation. To avoid interfacial reactions between Ni and the overlayer, a Ta diffusion barrier had been inserted. Fig. 5 shows a voltamogram (IV characteristics) of the electrode (structure fig. 6), also in comparison to a typical a Pt electrode. The water dissociation window of $3.0 \mathrm{~V}$ and the low background current indicate the absence of any graphitic phases and pinholes, acting as metallic shorts.

To our knowledge this is the first successful attempt to overgrow a GaN-based heterostructure by high quality nanocrystalline diamond of high structural quality, opening a pathway to a number of novel concepts to III-nitride device structures.

References:

[1] A. V. Sumant, et al. "Demonstration of low temperature ultrananocrystalline diamond (UNCD) film integration with CMOS devices for monolithically integrated diamond MEMS/NEMS-CMOS systems” NDNC 2007, abstr. 5-2, Osaka (Japan)

[2] G.M. Swain; "Electroanalytical applications of diamond electrodes"; Thin Film Diamond II (Semiconductor and Semimetals vol. 77), Chapter 4, Elsevier 2004 
[3] F. Medjdoub, et al. “Can InAlN/GaN be an alternative to high power / high temperature AlGaN/GaN devices?”, Int. Electron Devices Meeting (IEDM), Tech. Digest, 927, 2006

[4] W. Haenni, P. Rychen, M. Fryda, C. Comninellis; ’Industrial Applications of Diamond Electrodes”; Thin Film Diamond II (Semiconductor and Semimetals vol. 77), Chapter 5, Elsevier 2004

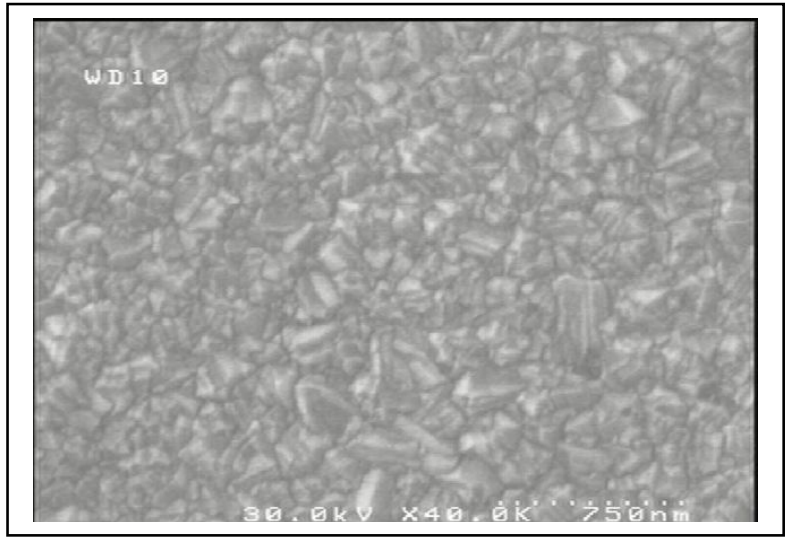

Fig. 1: SEM morphology of $200 \mathrm{~nm}$ nanodiamond on InAlN/GaN Fig. 2: Raman spectrum of $200 \mathrm{~nm}$ nanodiamond on InAlN/GaN

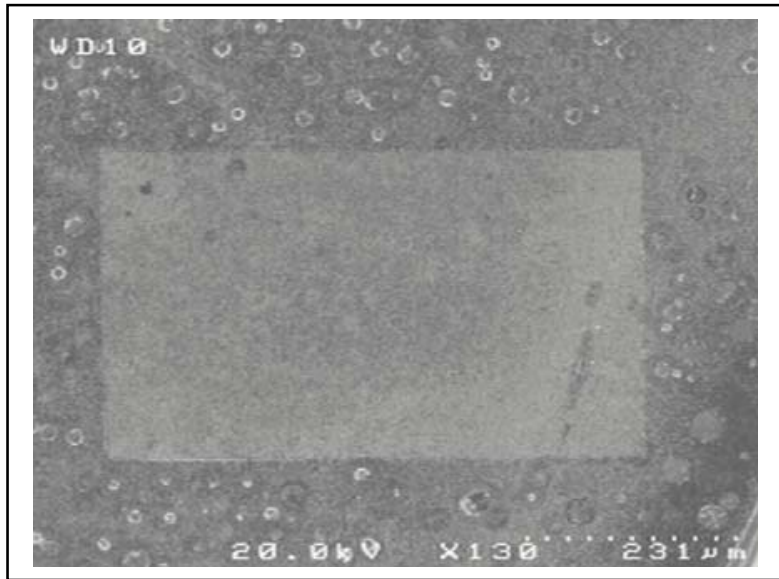

Fig. 3: MESA structure of InAlN on GaN after diamond growth

Fig. 4: Output characteristics of InAlN/GaN FET after $200 \mathrm{~nm}$ NCD growth at $700{ }^{\circ} \mathrm{C}$ and removal. $\mathrm{L}_{\mathrm{g}}=500 \mathrm{~nm}, \mathrm{~W}_{\mathrm{g}}=50 \mu \mathrm{m}$

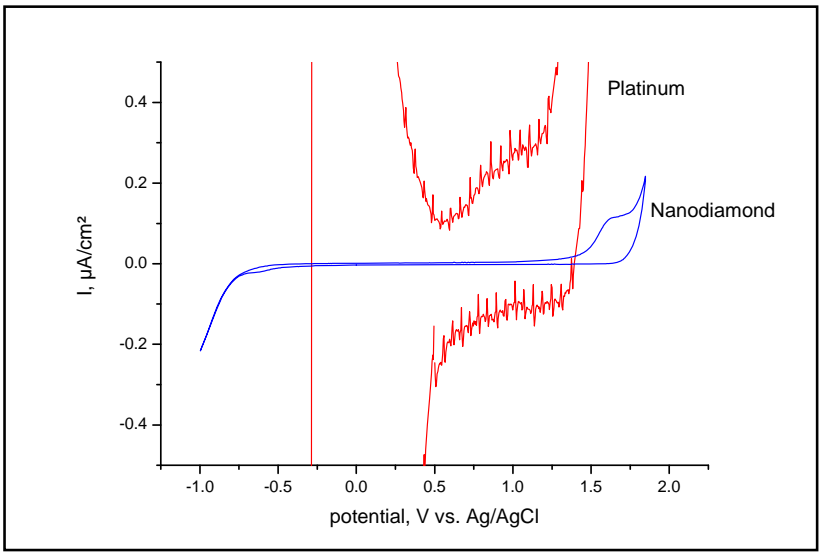

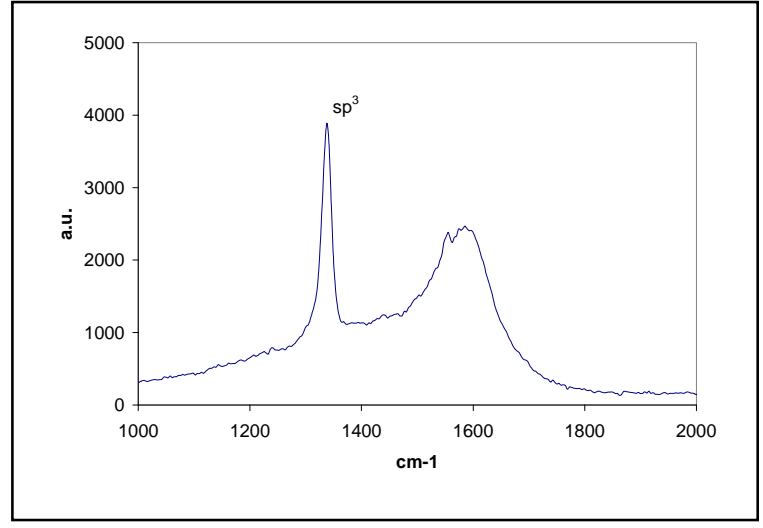
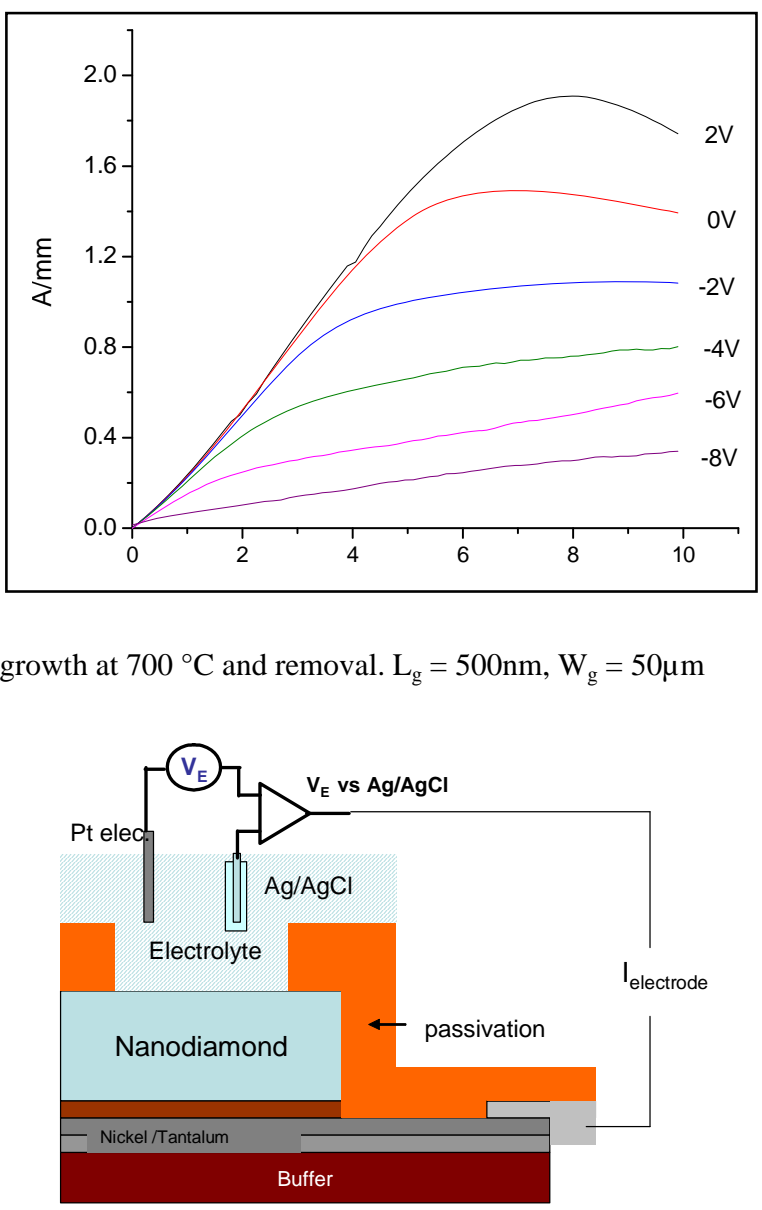

Fig. 5: Cyclic voltammetry of nanodiamond grown on Ni/Ta/a-Si in comparison with Platinum electrode Fig. 6: Sketch of the structure used for the Cyclic voltammetry measurement.

Acknowledgement:

This work was supported in part by the European Union Marie Curie Network DRIVE (512224) and the European Union Research Project ULTRAGAN. 